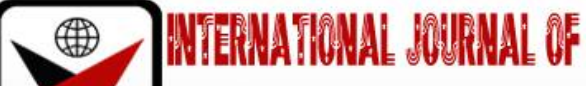

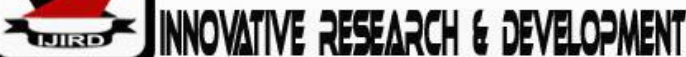

ISSN 2278-0211 (Online)

\section{Design and Construction of a Multipurpose Device for Doming and Punching}

Isaac Kwabena Agyei
Lecturer, Department of Industrial Art,
College of Art and Built Environment, KNUST, UPO, Kumasi, Ghana
Dr. Peggy Ama Fenning
Senior Lecturer, Department of Industrial Art,
College of Art and Built Environment, KNUST, UPO, Kumasi, Ghana
Kofi Adjei
Senior Lecturer, Department of Industrial Art,
College of Art and Built Environment, KNUST, UPO, Kumasi, Ghana

\begin{abstract}
:
Metal work comes along with a lot of techniques which doming is not an exception. Doming techniques use doming block and punches to create metal domes for production of unique artifacts. These doming blocks and punches come in a shape of half round. The challenge has always been getting different shapes of domes and their corresponding punches to give a variety and creativity in design of metal works and the energy one needs to give, a lot of hammer blows to be able to achieve the domed metal. This project or research seeks to design and construct a multipurpose portable device or machine for doming and punching. The portable device is going to be operated manually (mechanically), which means without electricity which is bedeviled by power fluctuations in most African countries, the device could still be operated with the needed efficiency and technique. The tip of the device is adjustable so it can be changed to get the desired shape the operator wants. There is a disc-like plate that corresponds to the tips or the punches. The device is designed to have a small cabinet of which the punches can be kept. It is designed to have a handle hanged by it side of which pressure or force is applied to create the impression or the punches desired. The material used for this device is iron the metal working technique used is welding. This study made use of quantitative research design by using descriptive and studio-based research. Findings revealed that it is possible to get domes of different shapes and sizes with their corresponding punches which can easily be used to achieve various domed designs to foster creativity in design and fabrication of metal art works. This device is designed and constructed to help metal students of Kwame Nkrumah University of Science have variety of shapes as regards doming and punching as a technique of metal work. The study recommends that metal art students and practitioners alike should make use of this device to augment the technique of metal art. Again, it is recommended that apart from the device being operated mechanically, power options such as gas could be tried so that human effort could be minimized.
\end{abstract}

Keywords: Construction, doming block, doming punches, multipurpose, mechanical, device

\section{Introduction}

In research or projects of such nature, the design is very paramount. Ford (2001) opines that design can be defined by the consideration of the formation of a machine or a building for a particular usage. It's equally recognized to be the roadmap to the achievement of a unique expectation since it harbors the specifications as well as the parameters to be involved in the finishing of a product or project such as this multipurpose doming device. The importance of design has been recognized by scholars from different field such as artificial science and engineering (Simon, 1969; March \& smith, 1995; Hernia et al. 2004) innovation and statistics (Petroski, 1996; Walsh, 1996; Verganti, 2003) management (Potts \& Cunnigham, 2008; Potts, 2009) despite a shared understanding of the role of design as a potential enabler of innovation, it still knowledge a wide range of meanings. Designing for such a multipurpose doming device is very crucial because the performance and the efficiency is imbedded in the nature of the design.

Construction which is a whole industry is brought to bear to make practical the design of the device so that this research would be beneficial to metal artists and students in the profession or industry. The construction industry is a strategic field which contributes tangibly to the economic growth of a developing country like Ghana (Sambasivtan and Soon, 2007; Toor and Ogunlana 2008; Mahamid, 2013; Khanh and Kim, 2014). Metal construction industry in Ghana is very dynamic and flamboyant. This study seeks to capitalize on this and the availability of materials to construct such a doming device to help promote the metal working industry and education in Ghana as a whole. 
The device which is said to be multipurpose is meant to produce different shape of domes with varying sizes, different punches with varying tips as well as compartments where punches are kept in the same device.

A device is a contrivance or an invention serving a particular purpose, especially a machine used to perform one or more relatively simple task. Again, a device can be an object or a piece of equipment that has been designed to do a particular job such as for doming purposes in metal art.

Untracht (1985) agrees that dome in its fullest and most perfect form is a hollow metal hemisphere of any diameter or size. It can be an independent unit, in which case it is made from a disc blank cut out with a disc cutter. Domes can be divided into two kinds: simple and compound, depending on the use of Pendentives. Pendentives are triangular sections of a sphere used to blend the curved surface of a dome with the flat surfaces of supporting walls. In the case of the simple dome, the Pendentives are part of the same sphere as the dome itself; however, such domes are rare. In the case of the more common compound dome, the Pendentives are part of the surface of a larger sphere below that of the dome itself and form a circular base for either the dome or a drum section (Utracht, 1985). This study seeks to produce a multipurpose compound dome device.

A punch is a hard metal rod with a shaped tip at one end and a blunt butt end at the other which is usually struck by a hammer. A doming punch is used in conjunction with a doming block to make sphere or hemisphere out of sheet of metals. The punch is generally made of tool steel but can be made of wood, they come in a number of different sizes, and the punch size determines what size the finished product will be (Utracht, 1985). The general term punch covers a wide variety of tools used in many different techniques. They have a striking end, a shank and a working end. What classifies a tool as a punch is its manner of use: the striking end is struck to force the working end to move the metal. The tool that strikes it is usually a hammer. But alternatively can also be metal bar or a flat-surfaced hard-wood stick. Generally, the stock from which the tool the tool is made is a straight piece of tool steel, or brass or bronze rod. It can be round, square or rectangular, or triangular in cross section. Sometimes it is tapered toward the working end or toward the striking end. Punches are generally known by the operation they are designed to perform. Among these are punches are used for beading, bending, bezel forming, blanking, center marking, chasing, coining, curling, cutting, dapping, die stamping, doming, embossing, figure and letter punching, matting, outlining, patterning, perforating, planishing, repoussage, rivet head forming, stamping, signature punching and texturing (Utracht, 1985). Under this study, doming punches are well designed and constructed for use.

\section{Materials and Methods}

In such a research that requires design and construction of a multipurpose device for doming and punching, quantitative research design using descriptive and studio based approaches were employed. The research design for this study is considered by Leedy and Ormrod (2005) to generally be the complete structural arrangement for the processes follows by a researcher, the data the researcher collects and its analyses the researcher conducts to provide solution to identified problem. In his direction, research design provides fundamental direction to all the decisions that are made in planning the study which consist of the type of research strategies to use, the sampling procedure, the type of data sources and data collecting procedures and the data analysis plan. Thus, the research design shows how methodical and scientific the researcher addresses the main research questions of a research (Rubbin \&amp; Babbie, 1997; Trochim, 2006). Research design therefore is a definite pattern organization of a research at hand.

Best (2003) opines that qualitative research is usually concern on quality instead of quantity. Here the quality of the device for doming and punching is very paramount. According to Leedy et al. (2005) qualitative research study is relevant for the purposes including description, interpretation and verification of systems or people. These characterized by this type of research was the best option for this research study. This method was chosen because as regards the design and the construction of metal doming block and punches, quality is paramount and does not have to be compromised at all.

The descriptive method of research is used to describe settings, processes, situations, and for analysis and interpretation of collected data in this study. The Descriptive survey method of research was used for the study. This method was used extensively to collect, collate and interpret data. Descriptive research (Statistical research) provides data about the population or universe being studied (Davis, 2007). In another view, descriptive research is used to obtain information concerning the current status of the phenomena to describe what exists with respect to variables or conditions in a situation. But it can only describe the who, what, when, where and how of a situation, not what caused it. It provides the number of times something occurs, or frequency, lends itself to statistical calculations such as determining the average number of occurrences or central tendencies (Descriptive Research, 2008)

Leedy et. al (2005) explains that, descriptive research deals with the situation that demands the technique of observation as the principal means of collecting data. In this study existing doming blocks and punches were carefully observed.

Osuala (2005) defines observation as the act of recognizing, perceiving and noting facts specifics, details, realities, or occurrences by the use of the sense. Observation process essentially offers first-hand information without relying on reports of others.

Although descriptive research relies on observation for acquisition of data, the data must be organized and presented systematically so that valid and accurate conclusions can be drawn. It is a type of research that simply looks with intense accuracy at the phenomena of the moment and describes precisely what the researcher sees. Therefore, descriptive survey was used when the objective is to provide a systematic description of the phenomenon that is as factual and accurate as possible. This research was very expedient because the researchers had to critically observe and describe the already existing designs of doming blocks and punches to help come up with this project. 
Again, studio-based research was also employed since this involves a typical studio practice.

According to Marshall (2010), studio based research represents typically involves the production of artworks. The imaginative and intellectual undertaken by artists are considered to be forms of research and they are evaluated based on these five factors:

- Description of the subject matter of the artefacts produced.

- Identification of iconography.

- Notation on impact of selected media and methods of production.

- Principles of art and organization of visual elements such as line, colour, space, movement, time and composition.

- Description of styles or processes.

There are frameworks that every practical work must be followed and base upon which work must be evaluated and an attempt by artist to make research parallel with their work. Frameworks are being followed by Practitionerresearchers of which is referred trajectories of practice and research. Practice-based Research mostly aims to advance knowledge partly by means of practice. The type of research is an original investigation undertaken in order to gain knowledge and understanding. It includes the invention of ideas, images, performances and artefacts including design, where these lead to new or substantially improved insights. An effort to undertake it is included in a resulting knowledge which is embodied in an artefact. Whilst the significance and context of that knowledge is described in words, a full understanding of it can only be obtained with reference to the artefact itself. Artefacts in practice-based research can range from paintings and buildings to software and poems in which practice is a central focus and can be divided into two main types: practice-based and practice-led.

- If the research includes a creative artefact as the basis of the contribution to knowledge, the research is practicebased.

- If the research leads primarily to new understandings about the nature of practice, it is practice-led.

In some cases, both types of research appear together but there is usually one that is more dominant.

Practice-based Research is an original investigation undertaken in order to gain new knowledge partly by means of practice and the outcomes of that practice. In a doctoral thesis, claims of originality and contribution to knowledge may be demonstrated through creative outcomes in the form of designs, music, digital media, performances and exhibitions. Whilst the significance and context of the claims are described in words, a full understanding can only be obtained with direct reference to the outcomes. Such research includes practice as an integral part of its method and often falls within the general area of action research. This study falls under practice-based research because the study leads to design and construction of a multipurpose device.

\subsection{Tools, Materials and Equipment}

Practically oriented nature of research like this, tools, materials and equipment are very important since it involves the production of a device to function as a doming block and punches.

\begin{tabular}{|c|c|}
\hline Tools, Materials and Equipment & Purposes \\
\hline Figure 1 Mild Steel Figure & $\begin{array}{c}\text { Figure 1 which is a mild steel figure was used for } \\
\text { forming the main device }\end{array}$ \\
\hline Figure 2 Electrodes & $\begin{array}{c}\text { Figure 2 Electrodes were used to weld all the parts } \\
\text { of the device together with the aid of a welding } \\
\text { machine }\end{array}$ \\
\hline Figure 3 Stainless Steel Rod and a Spring & $\begin{array}{c}\text { Figure 3 which is the stainless steel rod was fixed in } \\
\text { the spring to facilitate movement of the shaft. }\end{array}$ \\
\hline & $\begin{array}{c}\text { Figure 4 These steel rods were used to forge the } \\
\text { punches }\end{array}$ \\
\hline Figure 4 Steel Rods & $\begin{array}{c}\text { Figure 5 is a flat chisel which was used to cut the } \\
\text { metal sheets into the desired shape to make the } \\
\text { device }\end{array}$ \\
\hline
\end{tabular}




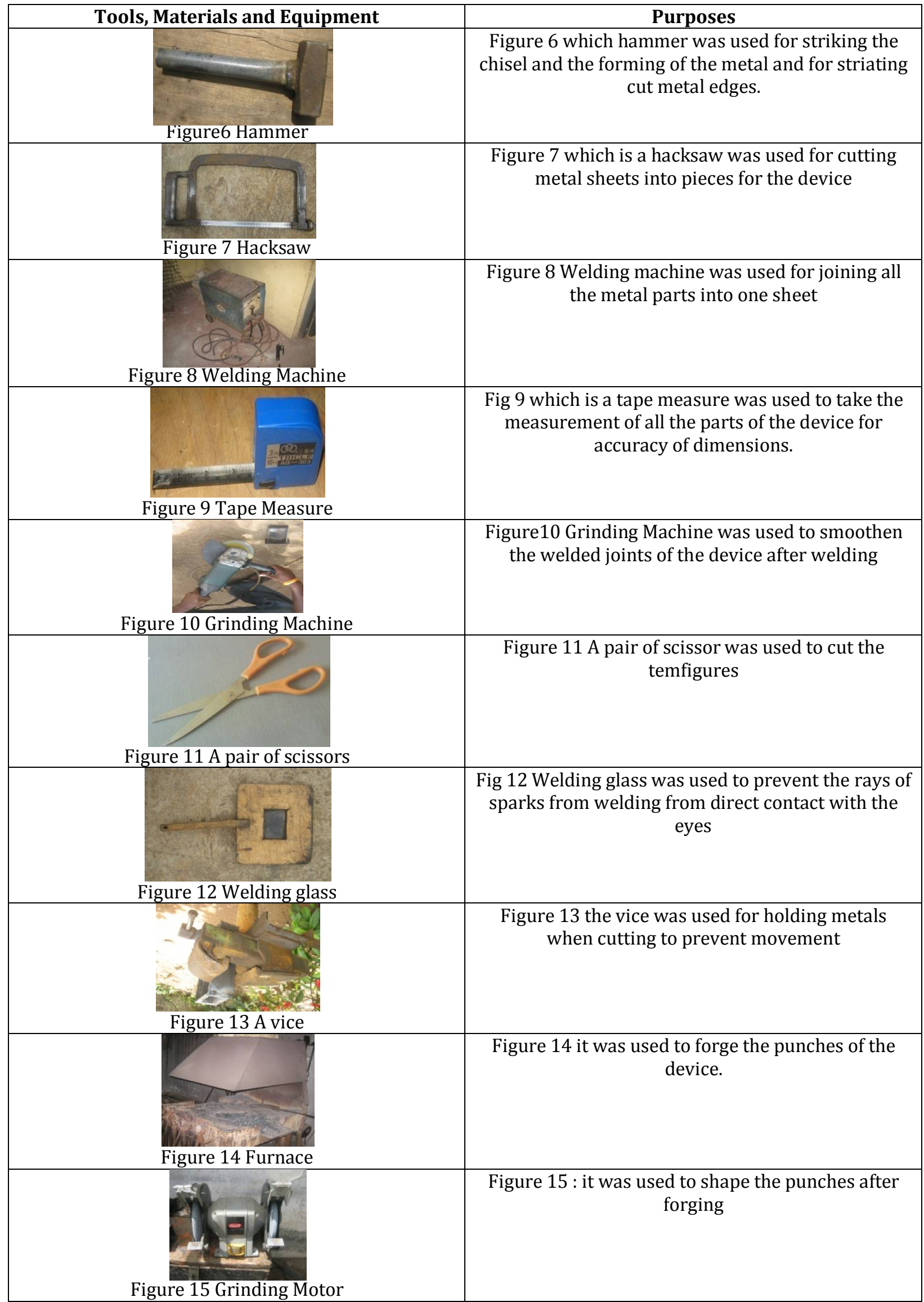

Table 1: Tools, Materials and Equipment and Their Purposes

\subsection{Design Processes}

With the idea of producing a functional multipurpose doming device for doming and punching, the researchers had to design and produce sketches that will really serve the purpose. Preliminary sketches were made and the final one which would serve the purpose was chosen accordingly. 


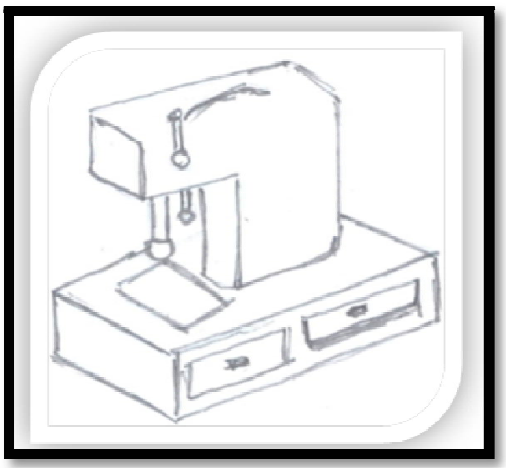

Figure 16: Sketch 1

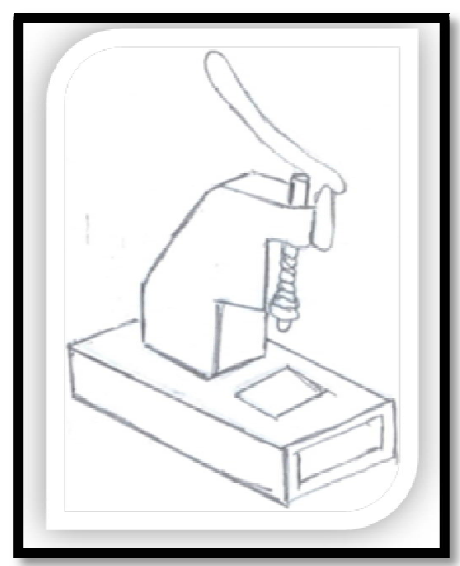

Figure 17: Sketch 2

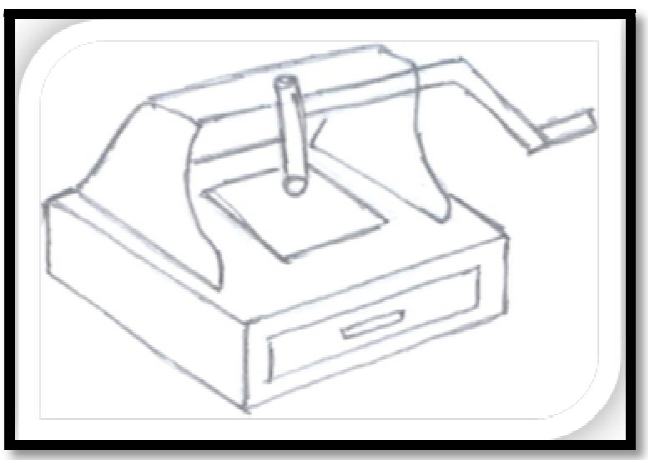

Figure 18: Sketch 3

After careful observation of all the three sketches ( fig. 1- fig.3). Fig. 3 was chosed as the best design to well suit the purpose of the project. After selection of fig. 3, the design was drawn into details with the necessary dimension and computer rendered as in fig. 4 .

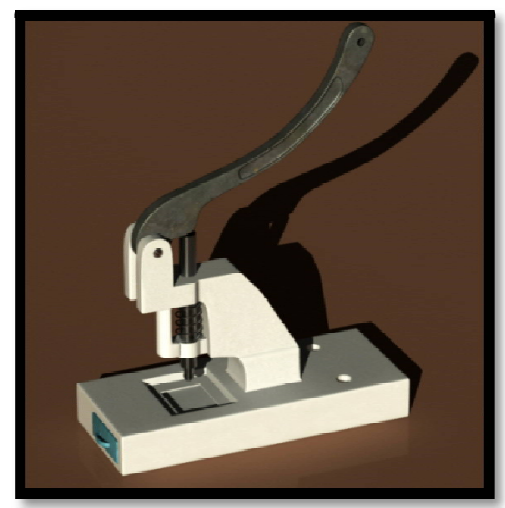

Figure 19: Computer Rendered Work 


\subsection{Cutting of Temfigures for Parts}

Cardboard was used to cut the temfigures of all the parts of the sheet for the construction of the device. Temfigures were cut according to the specific dimensions and traced unto the metal sheet to be cut to size.

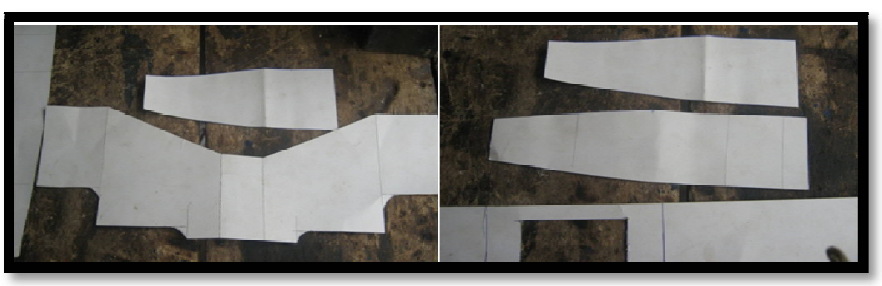

Figure 20: Paper Temfigures

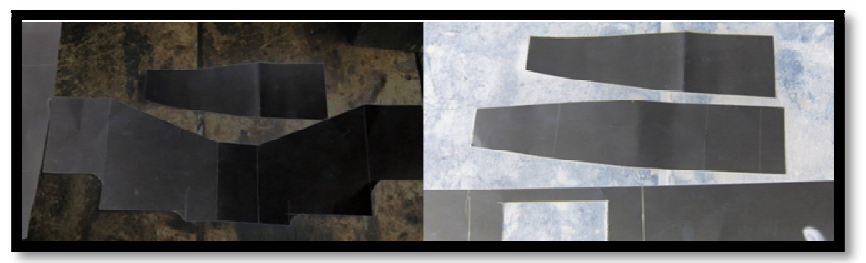

Figure 21: Metals Cut to the Desired Shapes Using the Paper Temfigures

\subsection{Construction Processes}

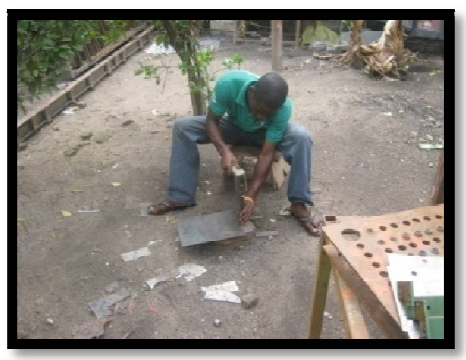

Figure 22: Folding of Edges

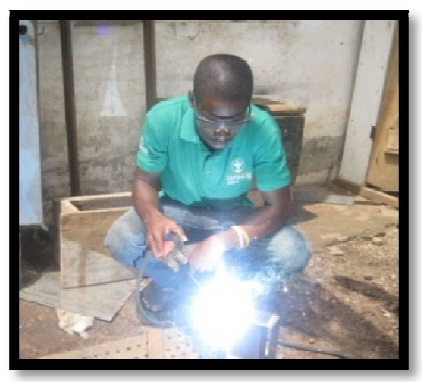

Figure 23: Welding

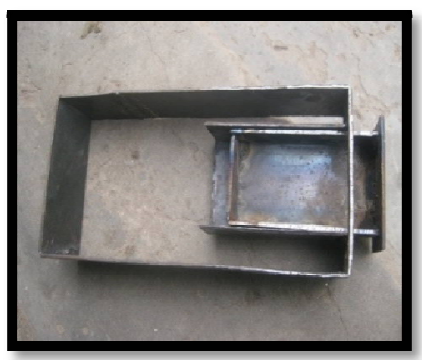

Figure 24: Base with Drawer 


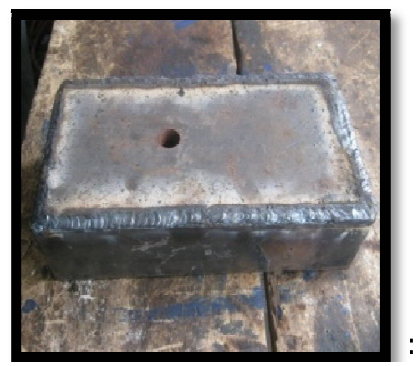

Figure 25: Seiling the Base

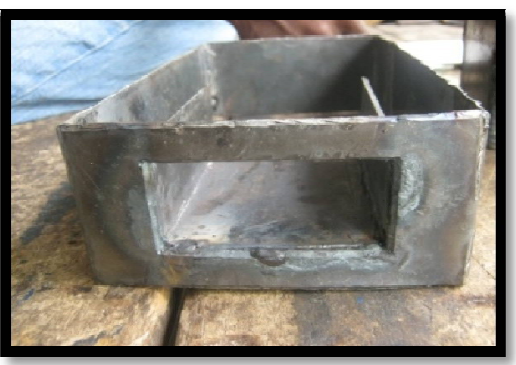

Figure 26:Putting the Base Together

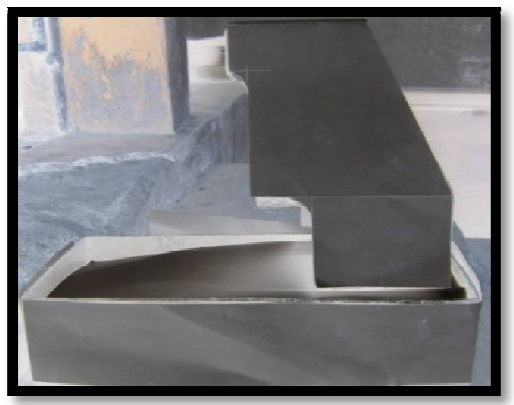

Figure 27: Base and Top

After cutting all the parts to size with the aid of the paper temfigure, marked parts were foldered (Figure 16) before welding all the parts together as seen in Figure 17. The drawer which is an integral part of the base as compartment to store the punches was also constructed as seen in Figure 18.

After the compartment was made, a figure was used to seal the base as shown in Figure 19. Figure 20 shows the base well welded together and Figure 21 also shows the top part of the device welded completely to the base.

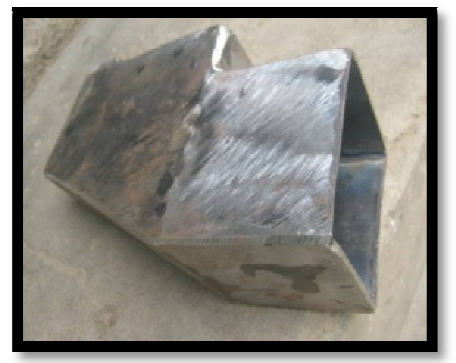

Figure 28:Neck of Device

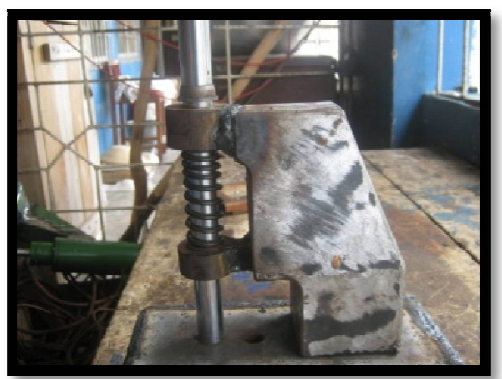

Figure 29: Springs Welded 


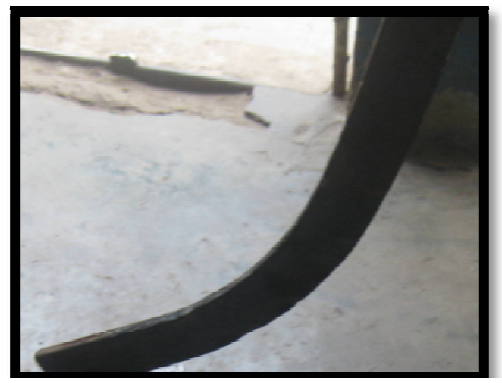

Figure 30: Handle Made

Figure 22 shows the neck of the device after it was weldered. The welded joints were grinded accordingly to make it lool smooth. The Spring mechanism to aid the mechanical funtion of the device for punching or the two rings holding the shaft and the spring were also welded and the shaft was placed correctly (Figure 23). The handle as shown in Figure 24 was also constructed and fixed. After welding the parts separately, the parts were assembled and welded together.The handle is designed to have an arc shape so it was removed, placed in a furnace to make red hot and forged to obtain the desired shape and fixed back.

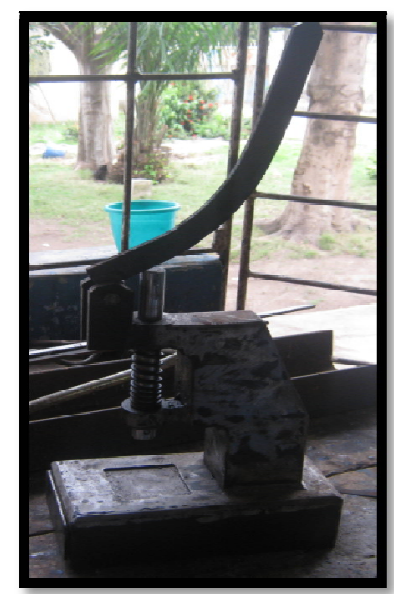

Figure 31: Device After Construction

Figure 25 is the device after construction with all parts intact. After the welding and grinding, filler was applied to fill all the holes on the device to make it smooth and finally sprayed or painted. In order to make the device functional and presentable, it has to come with its punches so steel rod was taken, cut into a suitable size and with the help of the furnace it was forged. After forging the punches, it was grinded, filed and polished to make them smooth

\section{Results and Discussion}

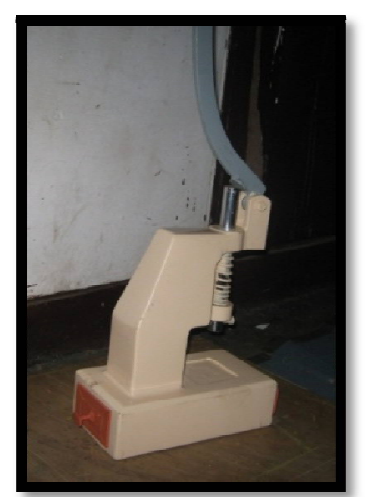

Figure 32: Device after

Construction and Finishing

Figure 26 is the main device after going through all the construction processes and finishing. The main purpose of which the researchers designed this multipurpose device was to help improve accuracy in punching and texturing of sheet metals and delicate works in the metal working industries and institutions that study metal art. The length of the device is $141 \mathrm{nches}$ and the width is 10 inches. The device is designed to use pressure when pressed sheet metals with its punches which corresponds to the disk. The disk was made of a very hard wood. The main reason behind this is students can carve their desired designs and use for their work. The device has two drawers of which the punches and the disk would be kept. A spring and a stainless steel shaft are fixed to facilitate the movement of the punches. The shaft is incorporated with 
threaded hole and a bolt which can help the changing of the punches. The device is painted light brown at the body, and the drawers painted brown just to create variety. Some of the interesting things about the device are; electricity is not needed to operate the device and also it works faster. Welding was used as a means of joining the parts of the device.

\subsection{Research Findings on Tools, Materials and Techniques}

In order to construct the device to meet the required standard, durable materials were required to be used so time was taken to search for the materials. The materials are $5 \mathrm{~mm}$ mild steel figure for the forming of the device, electrodes for the welding of the joint of the device, a spring and a stainless steel shaft to facilitate the movement of the punches, steel rods shaped to serve as punches, filler applied to seal holes on the device and paint sprayed on the device to serve as a finishing. $5 \mathrm{~mm}$ mild steel was very efficient and effective as the main material used to construct this device. The spring shaft is very efficient in its operation. Folding of the marked edges prior to cutting was tedious since there wasn't a solid metal block. So the folding was improvised.

Cutting is the act of dividing metal by penetrating it edgewise with a hand cutting tool that has a cutting edge or edges to make an incision or divide it into parts or with a manually operated power cutting tool to severe a portion. The use of the hacksaw to cut was very ineffective and therefore resorted to the use of the flat chisel in the cutting activity.

Arc welding is the predominant metal working technique used to construct the dome device. Arc welding is a part of welding or melting the metals to join metal parts at the welding point. In arc welding as the name suggests, an electric arc is created between an electrode and the material which is the base. This formation of arc is facilitated by the welding power supply.

Forging is a metal forming process whereby the work piece is heated red hot and placed between an anvil and a hammer and subjected to compressive force between them. This technique was used to shape the handle and the punches to get the edges smooth for better finishing. Forging was very efficient in the construction of this device.

Grinding machine was very instrumental in grinding all the edges of the welded joints to make such areas smooth.

Some of the pronounced challenges was that the metal sheet used for the work was very hard so it was very difficult to form the device mechanically. In the field of forging, the tongs needed to hold the red hot metals were not functioning well so when the metal was struck it bounced back to the researcher causing some serious injuries.

\section{Summary, Conclusion and Recommendation}

\subsection{Summary}

The study is done to construct a portable device which is going to be used as doming, punching and texturing. The idea behind the construction of this device is to help metal artists and students dome, texture and punch with ease. The punches of the device can be changed periodically depending on the type of work you want to do. The objective for the construction of this device is to help metal workers and students of metal to come out with different shapes of domes, textures and punches. So many techniques were used in the construction process, among which is forging and welding. Cutting of the sheet metal, which was done by using a hammer and a chisel, forming of sheet metal, welding, forging and grinding were all some of the techniques used in the construction of this device. Many problems were uncounted but after some hard days of working, the device has been constructed as the researcher designed it and it is functioning as expected and for that matter the researcher believes that the device will serve the purpose for which it was constructed.

\subsection{Conclusion}

The researchers' main objective was to construct a multipurpose device for punching, texturing and doming. This project was wheeled by the challenge such that domes normally come in one shapeswhen used and it takes quiet a longer time to finish with one dome.In the case of producing large number of works using the doming block, it will takequite a longer time to produce metal art works using the known doming blocks and punches. Descriptive and studio-based research were employed in this project. Design and construction stages were well followed and successful. All challenges were surmountable to make this research a reality. Metal working techniques such as welding and forging were used successfully to achieve the objectives of this study.

\subsection{Recommendation}

The researchers recommend that the device should be used by metal artists and students of metal art should be encouraged to provide project work which will foster creativity in the industry. It is again recommended that the device should be produced and send to the market for patronage in the metal industry. Metal works which would need the device should be encouraged to promote the device in the industry.

The jewelry industry is also recommended to patronize this device to help improve the technique and quality of works when it comes to producing works with domed styles and designs.

\section{References}

i. Best,J.W.(2003).Research in education. Englewood Cliffs, New Jersey: Prentice Hall Inc.,

ii. Davis, P. (2007). Systematic reviews in the social sciences: A practical guide. Blackwell Pub.

iii. Descriptive Research (2008). Descriptive research. Accessed from http://www.phac-aspc.gc.ca/publicat/cdicmcc/18-3/d_e.html [accessed March 23, 2018]

iv. Ford, T. (2001). Design innitiative. Johanisberg: J.J Publications 
v. Hernia, A., O’Donovan, P., Agarwala, A., and Hertzmann, A. (2004). Usage of Artificial Intelligence in Today's Graphic Design. Online Journal of Art and Design, 6(4), 183-198

vi. Khanh, HD, Kim, SY (2014). Evaluating impacts of waste factors on project performance Construction in Vietnam. KSPE J Civil Eng. 18(7):1923-1933

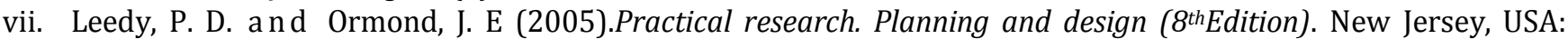
Pearson Prentice Hall Publications.pp.87-90

viii. Marc, S.T. and Smith, G.F. (1995). Design and natural science research on information technology. Decision Support Systems, 15 (1995)251-266

ix. Marshall, C. (2010). A research design for studio-based research in art, Teaching Artist Journal, 8(2), 77-87

x. Mohamid, I. (2013). Common risks affecting time overrun in road construction projects in Palestine: contractor's perspective. Autr J Contr. Econ Build. 13(2): 45-53

xi. Osuala,E.C.(2005). Introductiontoresearchmethodology (3 ${ }^{\text {rd }}$ edition).Nigeria:Africana-First Publishers Limited. p. 176

xii. Petroski, H. (1996). Invention by Design: How Engineers Get from Thought to Thing, Harvard University Press, Cambridge

xiii. Potts, J. and Cunningham, S. (2008). Four models of the creative industries. International Journal of Cultural Policy, 14(3), 233-248

xiv. Potts, J. (2009). Why the creative industries matter to economic evolution. Economics of Innovation and New Technology, 18(7-8), 633-674

xv. Rubin, H. J. and Babbie, I.S. (1997). Qualitative Interviewing: The Art of Hearing Data (2nd ed.), Thousand Oaks, CA: Sage Publications.

xvi. Sambasivan, M; Soon YW (2007). Causes and effects of delays in Malaysia construction industry. Int $j$ Proj. Mange. 25(5):517-526

xvii. Simon, H.A. (1996). The Sciences of the Artificial. MIT Press, London

xviii. Toor, SU; Ogulana, S (2008). Problems causing delays in the major construction projects in Thailand. Constr Mange Econ 26(4):395-408

xix. Trochim, W.M.K.(2006). Research methods knowledge base: Measurement validity types. Accessed from www.socialresearchmethods.net/kb/measval.phd [accessed October20,2018]

xx. Untracht,O.(1985).Jewelleryconceptsandtechnology.NewYork,USA:Doubleday.pp.22

xxi. Verganti, R.(2003). Design as brokering of languages: innovation strategies in Italian firms. Des. Manag. J. 14, $34-42$

xxii. Walsh, V. (1996). Design, innovation and the boundaries of the firm. Res. Policy, 25, 509-529. 